\title{
The Impact of COVID-19 on Radiation Oncology and Cancer Care: A Perspective from the Cancer Belt Region of India
}

\author{
Sapna Marcus ${ }^{1}$ Rohit Mahajan ${ }^{1}$ \\ ${ }^{1}$ Department of Radiation Oncology, All India Institute of Medical \\ Sciences, Bathinda, Punjab, India
}

Address for correspondence Rohit Mahajan, MD, Department of Radiation Oncology, All India Institute of Medical Sciences, Bathinda 151005, Punjab, India (e-mail: rohit_mahjn@yahoo.co.in).

Asian J Oncol 2020;6:47-52

\begin{abstract}
Keywords

- cancer belt

- COVID-19

- radiation oncology

A pandemic coronavirus, termed severe acute respiratory syndrome coronavirus 2 (SARS-CoV-2), causes a respiratory illness called coronavirus disease 2019 (COVID-19) that is often severe or life threatening. Considering the low immunity status of cancer patients due to multimodality treatment, they seem to be more prone to COVID-19. Given the rapidity with which the novel coronavirus (SARS-CoV-2) is spreading, we can expect an increased burden of cancer patients diagnosed with COVID-19 at oncology treatment clinics and a need to address the issues associated. As of the date of this writing, United States has been witnessing an increase in confirmed cases, not far behind are the large outbreaks of European countries. Patients with cancer may have compromised immunity due to their disease or its ongoing treatment, and early reports suggest cancer is a risk factor for severe COVID-19. Since the outbreak in Wuhan, Chinese researchers have published on their experience with COVID-19 and have highlighted high-risk groups, including the elderly and patients with comorbidities, including cancer. In one of the largest series reported from Wuhan, elderly patients were at a higher risk for disease severity with an $8.0 \%$ case fatality rate in those aged between 70 and 79 years, and $14.8 \%$ in those aged 80 years and older. The case fatality rate for cancer patients in that cohort was notably higher than noncancer patients at 5.6 versus $2.1 \%$ in the whole sample. This review focuses on the pandemic-driven strategies that need to be adopted to overcome the radiation oncology clinics burden, especially in this region of India popularly termed as the cancer belt. Although colleagues around the world have dealt with enormous service pressures in the face of natural disaster or infection previously, the global scale and challenge of COVID-19 are unprecedented. Our aim is to highlight the quintessential point that even within these circumstances the morbidity and mortality associated with cancer should not be taken lightly. Departmental protocols should be regularly upgraded to provide smooth and efficient functioning of the department.
\end{abstract}

\section{Introduction}

Following a cluster of viral pneumonia cases in late 2019, a novel coronavirus was isolated and reported in Wuhan, China in 2020. This virus, now termed severe acute respiratory
DOI https://doi.org/

$10.1055 / \mathrm{s}-0040-1713960$

ISSN 2454-6798. syndrome coronavirus 2 (SARS-CoV-2), causes a respiratory disease called coronavirus disease 2019 (COVID-19) in infected individuals. Recent estimates of COVID-19 case fatality rates are around $2 \%$, rising to $15 \%$ in patients aged around 80 years or over., ${ }^{1,2}$ At present, no vaccine or specific 
antiviral therapy is available. The only measures available to prevent or delay community spread of COVID-19 are containment and rigorous case finding. Once COVID-19 becomes widespread within a community, quarantine and social distancing measures may slow its further spread, which have been adopted in many countries.

Patients with cancer could be at elevated risk of severe COVID-19, while delivery of cancer therapies could be disrupted by quarantines, social distancing measures, and disruption to routine healthcare delivery by the pandemic. Pending more definitive evidence, this article presents interim guidance, based on expert opinion, to aid decision-making for clinicians treating patients with cancers. The suggestions provided here may be relevant in both adult and pediatric patients as well. Cancer patients are more susceptible to COVID-19 in than individuals without cancer because of their systemic immunosuppressive state caused by the malignancy and the anticancer treatments, such as chemotherapy, targeted therapy, and immunotherapy. There will likely be more detailed studies of COVID-19 in future as currently a lot is still unknown about this disease and its mode of spread. In addition, there has not been any specific information on level 1 multicentric randomized trial including cancer patients and COVID-19. However, one study suggested a small percentage of patients had pre-existing conditions including diabetes (6.4\%, hypertension(12.8\%), cardiovascular disease (3.7\%), liver disease (2.7\%), malignancy (1.4\%), and others (3.7\%). ${ }^{4}$ As per the report of the World Health Organization (WHO)-China Joint Mission on COVID-19, cancer patients had an estimated twofold increased risk of COVID-19 than the general population. ${ }^{5}$

The inevitable presentation of a COVID-19-positive patient to a radiation oncology (RO) clinic promises to pose significant challenges to the staff, administration, and physician who are charged with not only with patient's care and well-being but also the care and well-being of other patients (and staff) in the department. - Table 1 depicts a hypothetical triage decision tree for a patient presenting to a RO clinic with a recent positive test for the COVID19 virus, informed by attentions to the Centers for Disease Control and Prevention (CDC) outpatient guidelines and the Bass \& Washington radiation facility infection control textbook chapter. ${ }^{6,7}$

\section{Complications during Radiotherapy Treatment}

1. Screening of incoming patients: Some clinics may opt screening for all patients upon immediate entry into the facilities, or even before entering, to decrease exposure risks. For COVID-19, suspicion for infection would be high in patients with fever, cough, shortness of breath, and/or a history of recent travel to high-risk areas. ${ }^{8}$ Our suggestion in this situation is that a questionnaire should be filled at the entrance asking all the relevant leading history for future reference.
Table 1 Challenges for radiation oncology during an outbreak of infectious disease

\begin{tabular}{|c|c|}
\hline Domain & Problem \\
\hline Patient groups & $\begin{array}{l}\text { Cancer patients may include vulnerable indi- } \\
\text { viduals due to use of chemotherapy or frailty } \\
\text { due to advanced disease These patients may be } \\
\text { colocated with relatively fit patients receiving } \\
\text { adjuvant therapies }\end{array}$ \\
\hline Staffing & $\begin{array}{l}\text { Delivery of radiotherapy requires very specific } \\
\text { skill sets that are not generic within an acute } \\
\text { hospital. Treatment units are therefore very } \\
\text { vulnerable to changes in staff levels due to } \\
\text { sickness. Radiation therapists in particular have } \\
\text { very regular close contact with a large number } \\
\text { of patients and are at high risk of exposure }\end{array}$ \\
\hline Environment & $\begin{array}{l}\text { Although most radiation oncology units are } \\
\text { having physical separation from other hospital } \\
\text { departments, there may still be a mixing of } \\
\text { several patient groups in a waiting area. Some } \\
\text { services may share waiting areas between } \\
\text { patients on active treatment and those in fol- } \\
\text { low-up. Treatment bunkers may contain a large } \\
\text { amount of equipment that in cases of potential } \\
\text { contamination may be time consuming and } \\
\text { difficult to clean }\end{array}$ \\
\hline Equipment & $\begin{array}{l}\text { Treatment relies on highly specialist equipment } \\
\text { that will usually treat high volumes of patients } \\
\text { in sequence }\end{array}$ \\
\hline Treatments & $\begin{array}{l}\text { Treatment courses are delivered in fractions } \\
\text { and efficacy is influenced by interruptions } \\
\text { and gaps. Extended treatments over many } \\
\text { weeks are more vulnerable to interruption } \\
\text { due to patient sickness or workforce shortage. } \\
\text { Chemoradiotherapy treatments also increase } \\
\text { likelihood of serious infection. Some treatments } \\
\text { given for palliation or as adjuvant therapy may } \\
\text { have altered risk benefit in the context of pan- } \\
\text { demic infections }\end{array}$ \\
\hline
\end{tabular}

2. Increased diagnostics: Diagnosis can be made by specific reverse transcription polymerase chain reaction of nasopharyngeal or oropharyngeal swabs and lower respiratory tract samples with median viral shedding of 20 days (interquartile range: 17-24 days). ${ }^{9}$ Upon finding patient positive leading history on the questionnaire at the entrance the patient should be reviewed at the medicine department before receiving treatment

3. Increased taxation on the pre-existing burden: Furthermore, RO clinics are uniquely taxed by an extra population of patients reporting to waiting rooms for daily radiation treatments. The large number of potential appointments and/or daily treatments, in addition to a pre-existing disease state, heightens the risk faced by already at-risk ongoing treatment patients. Based on survey results from Chinese hospitals, $88 \%$ of radiation oncologists said that they would provide radiation treatment for patients with negative screening results, while others said that they would not provide treatment.

4. Delay in treatment delivery: Opinions vary with regard to length of the necessary isolation period before the delivery of radiation therapy to asymptomatic patients with an 
epidemic travel history. In a study, 70\% hospitals believe that asymptomatic patients could be treated after 14 days of isolation, $2 \%$ suggest that 24 days are necessary, $1 \%$ demand 30 days, while the other $27 \%$ say they would not provide radiation therapy to these patients for the time being. ${ }^{10}$ For confirmed COVID-19 patients who have been cured, all hospitals showed a more cautious attitude. Up to $39 \%$ of hospitals indicated that they would not provide radiation treatment for them, and the proportion of hospitals that believed they could start radiotherapy (RT) after isolation for 14,24 , or 30 days was 24,10 , or $27 \%$, respectively. The most important and worrisome attitude in the delaying of treatment during the long isolation periods are the compromises we are bound to make in the radiobiological benefits to cancer patients, some of whom would not start timely treatment and others of whom would not experience the optimal biological effects of radiation therapy due to delays in treatment.

5. Setup of different treatment delivery counters with dedicated linacs: Another consideration is that of the shared treatment machines. It is therefore imperative that RO clinics review established infection control protocols and adapt necessary unique considerations of SARS-CoV-2 in the healthcare settings. ${ }^{11}$ Unique consideration in RO may include apt and repeated sterilization of active breathing control devices, handles from arm positioning, and any attachment of the treatment couch that contacts the patient. Attention should also be paid to the times that facilitate appropriate sterilization of the staff and minimize time of exposure. Finally, cognizant efforts must be made to discard potentially contaminated personal protective equipment (PPE) and/or garments prior to leaving the hospital so as to carry viral particles outside.

6. Impact of treatment interruptions: Radiation oncologist will also have to prepare for treatment interruptions. Patients who test positive for the novel coronavirus will, at the minimum, require a 14-day quarantine per CDC recommendations. ${ }^{12}$ Treatment interruption may be due to multiple reasons in which hospitalization due to symptoms is the commonest as immunosuppression is very common in cancer patients. Data from a report of the clinical characteristics of patients with the COVID19 showed that $6.1 \%$ of patients required intensive care, mechanical ventilation, or died..$^{13}$ Second, they may be isolated due to travelling difficulties or intercity lockdowns. These treatment interruptions would be of utmost concern for tumors in which overall treatment time significantly impacts outcomes such as head and neck cancers and cervical cancers. ${ }^{14,15}$ On the other hand, treatment delays may also be due to strains on the healthcare system in the setting of a pandemic due to travel restrictions, availability of workforce, and/ or lack of access to hospital care. ${ }^{16}$ If possible, travel restrictions for the general public should be tailored for patients with cancer, such as being done currently in Italy.$^{17}$ This is the principle which is being currently adopted at Malwa region by the joint efforts of local administration and radiation oncologists so as to make thing as convenient as possible for the cancer patients in this region and to minimize the pain and cost issues.

Little data exists currently to guide radiation treatment decisions in the setting of the pandemic. However, we may borrow insight from the response of RO clinics during Hurricane Maria which happened in 2017 at Puerto Rico and was devastating for all forms of medical practices. As per Gay et al, mitigating the impact of a natural disaster on cancer patients requires four components or "PCOC": prepare, communicate, operate, compensate. ${ }^{18}$ The

The steps of PCOC are as follows:

1. Prepare: The preparation phase is critical in minimizing the treatment delays that may result from natural disasters. A standard protocol should be established for changes in treatment plans with combined intervention of colleagues in physics, planning, and treatment. To look for areas where workforce can be reduced by reducing the number of fractions and treatment courses. Make personal protective devices and masks along with sanitizers available to the frontline workforce.

2. Communicate: Because of the complex nature of daily RT, a RO practice requires effective communication between the RO, facility staff and patients and between the computer servers and linear accelerators. If the RT center is closed, the patient listed on the roll call should be called up and informed. Patients should be given USB flash drive copies of their medical records and digital imaging and communication in medicine datasets. Flash drives are portable and robust and allow patients to optimally resume care at another local facility or abroad. If not done, the new radiation oncologist may face a challenge of not knowing the previous dose delivered, treatment plan, and other vital medical information. As conditions improved, patients may be seen at RO clinics with only written treatment and clinical history summaries.

3. Operate: The frontline staff needs to be consolidated into small functional groups that do not depend on other groups and do not move to different clinical areas. Consider temperature screening for all users of the RT center. The information regarding COVID positive cases should be disseminated quickly and it should be a departmental call to continue, stop, or pause the treatment.

4. Compensate: Under the leadership of Brian Kavanagh, $\mathrm{MD}, \mathrm{ASTRO}$ president, experts in various disease sites were asked how to best mitigate the impact of a 2- to 3-week interruption in treatment. This generated an e-mail discussion among the disease site experts. The recommendations were compiled and further refined by all the experts who participated in the discussion. When radiation treatment is paused, compensation on treatment restart is required according to radiobiological models and the $\alpha$-beta ratio. Where there is no survival benefit, RT treat-

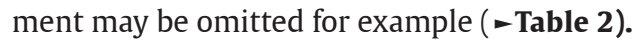


Table 2 Diseases where radiotherapy treatments may be omitted

\begin{tabular}{|c|c|c|c|}
\hline Disease site & Subsite/Classification & Modality & Comments and evidence \\
\hline Breast & $\begin{array}{l}\text { Breast conservation } \\
\text { DCIS } \\
\text { Invasive disease } \\
\text { Low risk older patients } \\
\text { Invasive disease Genomic profile } \\
\text { low risk } \\
\text { Age }>50 \text {, ER+, Her2- breast ca } \\
\text { without other adverse pathologic } \\
\text { features } \\
\text { Post mastectomy T1-2 N1 } \\
\text { (node + breast cancer) }\end{array}$ & $\begin{array}{l}\text { Omission of radiotherapy to } \\
\text { whole breast }{ }^{19} \\
\text { Omission of radiotherapy to } \\
\text { whole breast }{ }^{20,21} \\
\text { Omission of radiotherapy to } \\
\text { whole breast } \\
\text { Omission of boost } \\
\text { radiotherapy }{ }^{22,23} \\
\text { Omit radiotherapy }\end{array}$ & $\begin{array}{l}\text { No survival benefit, small benefit in locore- } \\
\text { gional recurrence } \\
\text { Endocrine therapy only sufficient in > } 70 \text { (>65 } \\
\text { in PRIMEII) }{ }^{20} \\
\text { LUMINA, IDEA, PRECISION, PRIMETIME trials } \\
\text { ongoing (caution outside of trial) } \\
\text { No survival benefit } \\
\text { NSABP B-51/RTOG } 1304 \text { trials ongoing }\end{array}$ \\
\hline CNS & $\begin{array}{l}\text { Glioblastoma age }>60, \\
\text { methylated } \\
\text { Low-grade glioma } \\
\text { Asymptomatic meningioma } \\
\text { Gr 1-2 Asymptomatic AVM }\end{array}$ & $\begin{array}{l}\text { Temozolomide only } 24,25 \\
\text { Omit radiotherapy } \\
\text { Omit radiotherapy } \\
\text { Omit radiotherapy }\end{array}$ & $\begin{array}{l}\text { Standard radiotherapy associated with poor } \\
\text { outcomes }\end{array}$ \\
\hline Esophagus & & $\begin{array}{l}\text { Resection or chemoradia- } \\
\text { tion rather than trimodality } \\
\text { therapy }\end{array}$ & \\
\hline Gastric & $\begin{array}{l}\text { Resectable } \\
\text { Unresectable }\end{array}$ & $\begin{array}{l}\text { Treat with chemotherapy } \\
\text { only } \\
\text { Treat with chemotherapy } \\
\text { only }{ }^{26}\end{array}$ & \\
\hline Lung & SCLC, extensive & $\begin{array}{l}\text { Omit prophylactic cranial } \\
\text { irradiation } 27\end{array}$ & $\begin{array}{l}\text { Also consider omission of consolidation tho- } \\
\text { racic radiotherapy in extensive stage disease }\end{array}$ \\
\hline Pancreas & Unresectable & Omit radiotherapy ${ }^{28}$ & Consider chemotherapy or clinical trial \\
\hline Prostate & Low, favorable intermediate risk & Active surveillance 29 & \\
\hline Benign Disease & $\begin{array}{l}\text { Keloid, heterotopic ossification, } \\
\text { actinic keratosis }\end{array}$ & Omit radiotherapy & $\begin{array}{l}\text { Not life-threatening, topicals (NSAIDS) may be } \\
\text { reasonable alternatives (versus delay in the far } \\
\text { future) }\end{array}$ \\
\hline Palliative & $\begin{array}{l}\text { Painful mets, uncomplicated, } \\
\text { other systemic options } \\
\text { Oligometastatic (e.g., prostate } \\
\text { cancer) } \\
\text { Postoperative radiotherapy (for } \\
\text { pathologic fracture) } \\
\text { CNS mets from NSCLC needing } \\
\text { WBRT }\end{array}$ & $\begin{array}{l}\text { Omit radiotherapy } \\
\text { Omit radiotherapy } \\
\text { Omit radiotherapy }\end{array}$ & $\begin{array}{l}\text { Ensure medical optimization (e.g., WHO Pain } \\
\text { Ladder) } \\
\text { Systemic treatment, for example, androgen } \\
\text { deprivation therapy } \\
\text { Limited/evidence of benefit } \\
\text { Best supportive care including steroids }\end{array}$ \\
\hline Testicular & Seminoma, stage I & Omit radiotherapy & Consider observation or carboplatin \\
\hline
\end{tabular}

Abbreviations: AVM, arteriovenous malformations; CNS, central nervous system; DCIS, ductal carcinoma in situ; NSAID, nonsteroidal anti-inflammatory drug; NSCLC, nonsmall cell lung cancer; WBRT, whole brain radiotherapy; WHO, World Health Organization.

\section{Brachytherapy}

While brachytherapy can be hugely effective as a treatment and it often saves patients significant hospital time receiving equivalent external beam RT, it may prove challenging to deliver. Brachytherapy may also increase the risk of transmission during intubations or upper endoscopic procedures and necessitate increased PPE when they are in short supply. Therefore, brachytherapy may be a preferred oncological option in many cases but it may be impossible to deliver. In certain cancers (e.g., vaginal vault boost or prostate cancer brachytherapy) it may be prudent to plan for external beam alternatives if necessary.

Most, if not all, patients who resume treatment at another facility will benefit from a resimulation because positioning systems or treatment equipment may be different, the tumor may have changed in size during the treatment break, and the patient may have lost weight. The most recent cone beam computed tomography (CT) scan can be helpful in assessing changes between the last treatment and the new simulation. Fusing the original structure set with the new planning $\mathrm{CT}$ will expedite the contouring process and maintain consistency with the original intended volumes. In the ideal scenario where the gross tumor volumes (GTVs) have not changed much and are covered well by the original planning target volume (PTV), the PTV is cleaned from fusion artifacts and the skin minus a $3 \mathrm{~mm}$ contour is subtracted from the PTV, as in the case of a head and neck intensity modulated RT plan. Substantial changes in the GTV will require a new GTV, clinical target volume, and PTV. Organ-at-risk contours can be inspected and edited as necessary to reflect changes in anatomy or patient positioning. Having a clear understanding of when a local facility may become operational again is critical. For example, a patient 
with prostate cancer might be better served waiting a few days or weeks, aided by androgen deprivation therapy, before resuming treatment locally rather than waiting for a longer period of time to get a flight before encountering further delays from a second consultation, simulation, and treatment planning, potentially with incomplete local medical records. A patient with head and neck cancer, for whom time is critical and who has no realistic local option in the foreseeable future, may be better served seeking treatment abroad, depending on the situation.

These are rough guidelines based on the limited evidence available.

In the end, patient contact should be rationalized as much as possible and departments may wish to map the patient flow through their department and see what proactive steps can be made to reduce the contact of patient with number of staff members a patient may need to have contact with. Equally, staff movement around multiple areas of the department should be restricted as far as practicable to avoid spread of infection among all staff members. Staff should be included in discussions around the changes in practice, such as the fractionation policies described here. Regular communication should be sent, preferably in an electronic bulletin. All staff should be aware of their responsibilities to report infective symptoms and self-isolate if symptomatic.

If it is not oncologically reasonable to pause or stop a patient's RT treatment (e.g., radical treatment of a squamous cell cancer of head and neck or cervix), then staff and other patients must be protected against the risk of cross infection. If department size allows, then plan for a hot bunker-a treatment machine where all potential COVID-19 infected or suspected infected cases are treated preferentially; route these patients through the department by separate entrance and exit as (consider using emergency or rear exits as separate doorways for this group) their treatment should be concentrated at the end of the day so that adequate decontamination and cleaning procedures can take place overnight before treatment resumes the next day.

\section{Conflict of Interest}

None declared.

\section{References}

1 Dong E, Du H, Gardner L. An interactive web-based dashboard to track COVID-19 in real time. Lancet Infect Dis 2020;20(5):533-534

2 Gardner N. Mapping 2019-nCoV. Available at: http://www.arcgis.com/apps/opsdashboard/. Accessed March 12, 2020

3 Wu Z, McGoogan JM. Characteristics of and important lessons from the Coronavirus Disease 2019 (COVID-19) outbreak in China: summary of a report of 72314 cases from the Chinese Center for Disease Control and Prevention. JAMA 2020;323(13):1239-1242

4 Cai Q Huang D, Ou P, et al. COVID-19 in a designated infectious diseases hospital outside Hubei Province, China. Allergy 2020:1-11

5 World Health Organization (WHO). Report of the WHOChina Joint Mission on Coronavirus Disease 2019 (COVID-19) 2020. Available at: https://www.who.int/publications-detail/ report-of-the-who-china-joint-missionon-coronavirus-disease2019-(covid-19). Accessed June 12, 2020

6 Basic Infection Control and Prevention Plan for Outpatient Oncology Settings. Atlanta, Georgia: Division of Healthcare Quality Promotion, National Center for Emerging and Zoonotic Infectious Diseases, Centers for Disease Control and Prevention. Available at: http://www.cdc.gov/hai/pdfs/guidlines/basic-infection-control-prevention-plan-2011.pdf. Accessed March 8, 2020

7 Bass LH, Washington CM, Infection Control in Radiation Control in Radiation Oncology Facilities. Principles and Practice of Radiation Therapy; 2015:178-218

8 What Healthcare Personnel Should Know about Caring for Patients with Confirmed or Possible COVID-19 infection. Centers for Disease Control and Prevention. Available at: http:// www.cdc.gov/coronavirus/2019-ncov/hcp/caring-for-patients. html. Accessed March 8, 2020

9 Zhou F, Yu T, Du R, et al. Clinical course and risk factors for mortality of adult inpatients with COVID-19 in Wuhan, China: a retrospective cohort study. Lancet 2020;395(10229):1054-1062

$10 \mathrm{Wu}$ JT, Leung K, Leung GM. Nowcasting and forecasting the potential domestic and international spread of the 2019-nCoV outbreak originating in Wuhan, China: a modelling study. Lancet 2020;395(10225):689-697

11 Interim Guidance for Healthcare Facilities: Preparing for Community Transmission of COVID-19 in the United States. Centers for Disease Control and Prevention. Available at: http://www.cdc.gov/coronavirus/2019-ncov/healthcare-facilities/guidance-hcf.html. Accessed March 8, 2020

12 Interim Guidance for Implementing Home Care of People Not Requiring Hospitalization for 2019 Novel Coronavirus (2019$\mathrm{nCoV})$. Centers for Disease Control and Prevention. Available at: http://www.cdc.gov/coronavius/2019-ncov/hcp/guidancehome-care.html?CDC_AA_refVal=https\%3A\%2F\%2Fwww.cdc. gov\%2Fcoronavirus\%2F2019-ncov\%2Fguidance-home-care. html. Accessed March 8, 2020

13 Guan WJ, Ni ZY, Hu Y, et al; China Medical Treatment Expert Group for Covid-19. Clinical characteristics of coronavirus disease 2019 in China. N Engl J Med 2020;382(18):1708-1720

14 Goel AN, Frangos MI, Raghavan G, et al. The impact of treatment package time on survival in surgically managed head and neck cancer in the United States. Oral Oncol 2019;88:39-48

15 Song S, Rudra S, Hasselle MD, et al. The effect of treatment time in locally advanced cervical cancer in the era of concurrent chemoradiotherapy. Cancer 2013;119(2):325-331

16 Wang H, Zhang L. Risk of COVID-19 for patients with cancer. Lancet Oncol 2020;21(4):e181

17 What to expect: Oncology's response to coronavirus in Italy Available at: http://cancerletter.com/articles/20200311-1/. Accesses March 12, 2020

18 Gay HA, Santiago R, Gil B, et al. Lessons Learned from Hurricane Maria in Puerto Rico: practical measures to mitigate the impact of a catastrophic natural disaster on radiation oncology patients. Pract Radiat Oncol 2019;9(5):305-321

19 Correa C, McGale P, Taylor C, et al; Early Breast Cancer Trialists' Collaborative Group (EBCTCG). Overview of the randomized trials of radiotherapy in ductal carcinoma in situ of the breast. J Natl Cancer Inst Monogr 2010;2010(41):162-177

20 Matuschek C, Bölke E, Haussmann J, et al. The benefit of adjuvant radiotherapy after breast conserving surgery in older patients with low risk breast cancer- a meta-analysis of randomized trials. Radiat Oncol 2017;12(1):60

21 Kunkler IH, Williams LJ, Jack WJ, Cameron DA, Dixon JM; PRIME II investigators. Breast-conserving surgery with or without irradiation in women aged 65 years or older with early breast cancer (PRIME II): a randomised controlled trial. Lancet Oncol 2015;16(3):266-273

22 Naoum GE, Salama L, Ho A, et al. The impact of chest wall boost on reconstruction complications and local control in 
patients treated for breast cancer. Int J Radiat Oncol Biol Phys 2019;105(1):155-164

23 Bartelink H, Maingon P, Poortmans P, et al; European Organisation for Research and Treatment of Cancer Radiation Oncology and Breast Cancer Groups. Whole-breast irradiation with or without a boost for patients treated with breast-conserving surgery for early breast cancer: 20-year follow-up of a randomised phase 3 trial. Lancet Oncol 2015;16(1):47-56

24 Malmström A, Grønberg BH, Marosi C, et al; Nordic Clinical Brain Tumour Study Group (NCBTSG). Temozolomide versus standard 6-week radiotherapy versus hypofractionated radiotherapy in patients older than 60 years with glioblastoma: the Nordic randomised, phase 3 trial. Lancet Oncol 2012;13(9):916-926

25 Wick W, Platten M, Meisner C, et al; NOA-08 Study Group of Neuro-oncology Working Group (NOA) of German Cancer Society. Temozolomide chemotherapy alone versus radiotherapy alone for malignant astrocytoma in the elderly: the NOA-08 randomised, phase 3 trial. Lancet Oncol 2012;13(7):707-715

26 Suzuki A, Xiao L, Taketa T, et al. Localized gastric cancer treated with chemoradiation without surgery: UTMD Anderson Cancer Center experience. Oncology 2012;82(6):347-351
27 Rusthoven CG, Kavanagh BD. Prophylactic Cranial Irradiation (PCI) versus active MRI surveillance for small cell lung cancer: the case for Equipoise. J Thorac Oncol 2017;12(12):1746-1754

28 Chauffert B, Mornex F, Bonnetain F, et al. Phase III trial comparing intensive induction chemoradiotherapy (60 Gy, infusional 5-FU and intermittent cisplatin) followed by maintenance gemcitabine with gemcitabine alone for locally advanced unresectable pancreatic cancer. Definitive results of the 200001 FFCD/SFRO study. Ann Oncol 2008;19(9):1592-1599

29 Hamdy FC, Donovan JL, Lane JA, et al; ProtecT Study Group. 10 years outcomes after monitoring, surgery, or radiotherapy for localized prostate cancer. N Engl J Med 2016;375(15):1415-1424

30 Willeumier JJ, van der Linden YM, Dijkstra PDS. Lack of clinical evidence for postoperative radiotherapy after surgical fixation of impending or actual pathologic fractures in the long bones in patients with cancer; a systematic review. Radiother Oncol 2016;121(1):138-142 